map directly from the country as copy, and renders unnecessary the making of elaborate notes, sketches, photographs, \&c., which is not only more expensive, but produces inferior results." As the instrument is perhaps not widely known in our own country, we may say that it consists of a drawing-board mounted on a tripod in such a way that it can be levelled, turned in azimuth, and clamped in any position. At the centre of the board is pivoted the alidade, consisting of a ruler with a graduated bevelled edge, to which is attached a pair of sights for rough work, or a telescope for work of a higher class. A small graduated arc is provided in the better-class instrument for the measurement of vertical angles, but the horizontal directions are plotted directly, by means of the alidade, on a sheet of paper stretched on the board. The edge of the board is set in the same direction when the instrument is in use at different points in the area being mapped, and horizontal locations are thus readily determined by intersections.

\section{LIFE AT THE ZOO.'}

A SIGN of the increasing interest shown by the outside world in all questions concerning life, and more especially animal life, is evidenced by the far greater number of books published every year on popular natural history.

The past year witnessed the commencement of several large works, such as the "Royal Natural History," edited by Mr. Lydekker; the republication of "Jardine's Naturalists' Library," edited by Dr. R. B. Sharpe; and the "Cambridge Natural History," of which, so far, only one volume has appeared. Besides these there have been issued a number of smaller works not extending over so wide a ground.

The present volume consists of a number of short articles on various natural history topics more or less directly connected with the Zoological Society's Gardens, illustrated with reproductions of some of Gambier Bolton's successful photographs of the animals found there. A

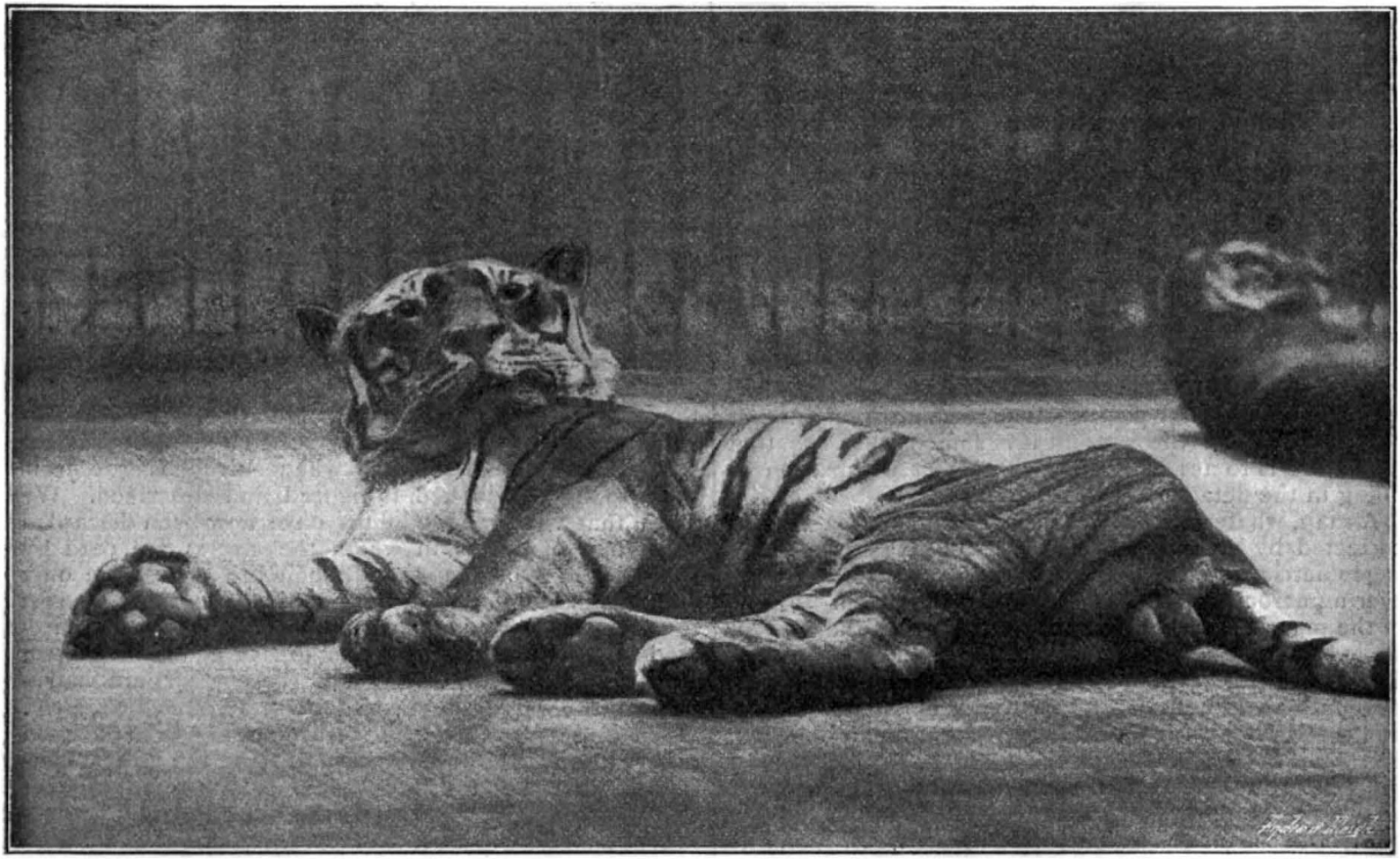

FIG, I.--The Tiger listening to suft music.

The simple form of plane table is now exclusively used by the Survey for the ordinary traverse work. Distance measurements in this class of work are made in the usual way by counting the revolutions of a wheel, an "odometer" being used for this purpose.

The manual abounds in practical hints on the various points connected with surveying, and concludes with a brief account of the office work which is so important a supplement to work in the field.

The numerous appendices consist of tables to be used in the various computations, and are complete enough to include even a table of logarithms.

It is not too much to say that Prof. Gannett has produced a manual which will be of interest to many not actually engaged in surveying, while at the same time it forms a very valuable supplement to the ordinary works on the subject.

No. I 316 , vol. 5 I]
A. FOWLER. considerable number of these sketches have already appeared before in the pages of the Spectator, but many chapters have been added, and the whole forms a very agreeable repertoire of gossip, with, in some cases, pretensions to higher things in the shape of accounts of experiments on the æsthetics of the animal world.

One of the most interesting of the articles directly connected wilh the Zoo is that on "Elephant Life in England." The number of elephants now in Europe, chiefly in circuses and menageries, is considerable. Mr. Cornish gives it at about 120 , of which England possesses about thirty-four. With some half-dozen exceptions, all these elephants belong to the Indian species, and are mostly imported from Burma, where they are bred in a half-wild state. The African elephant, according to our 1 " Life at the Zoo. Notes and Traditions of the Regent's Park Gardens." By C. J. Cornish. 8vo. (London: Seeley and Co., r895.) 
author, does not appear to possess quite so even a temper or so docile a nature as the Indian species, but still, judging from what has been done with them in our Zoological Gardens, there seems to be no reason why they should not be caught and tamed exactly in the same manner as their Indian relatives. Indeed, a few years ago an officer, in the service of the German colony of East Africa, made a special tour in India for the purpose of investigating whether it would be possible to introduce the keddah system into East Africa. Whether this enterprise has ever come to anything, does not appear to have transpired. It is also known that the subject occupied the attention of General Gordon shortly before his death.

In an article on the Wild Cats of the Zoo, Mr. Cornish discusses the origin of our domestic tabby. Besides the European Wild Cat (Felis catus), which now appears to be increasing slightly in numbers in Scotland, owing, doubtless, to the increased reservation of so much of the area of that country for deer-forests, he suggests the Chaus Cat of India and Northern Africa as a possible ancestor of our domestic form. There are, however, two other species, which both seem in many respects to have greater claims. One of these is the Cat of North Africa (Felis caffra or maniculata), a species held in veneration by the ancient Egyptians, large quantities of the mummified remains of which have been imported to this country for manure. An argument in support of the opinion that this is the true ancestor of the domestic cat, is the fact that the sole of the hindfoot of this species, like that of most varieties of domestic cats, is black, and not spotted, as in the European Wild Cat (Felis catus).

Another possible candidate for the ancestry of the domestic cat is the Waved Cat (Felis torquata); this cat has been obtained in various parts of India, Jut is never very common. It resembles very closely the Indian domestic breed. It is, however, more than probable that whatever the origin of the domestic cat may have been, it has interbred with the wild cats of the various countries to which it has been conveyed by man. This has certainly been the case in India, where hybrids between the native domestic cats and both the Jungle Cat (Felis chaus) and the Leopard Cat (Felis bengalensis) are fairly well known.

A plea for the repeal of the absurd and oppressive Act of Parliament that prohibits the use of dogs for draught purposes, forms another short essay. This Act was based entirely on the $\dot{a}$ priori and ridiculous argument that dogs "were not created" for such a purpose. Mr. Cornish shows that on the Continent, where dogs are freely used in this way, no ill effects ensue to them, and that their employment is an enormous boon to the poorer classes, who are unable to afford horses.

Several chapters of this work are devoted to the inhabitants of the Reptile House at the Zoo, and among them is specially mentioned the Heloderm, the only known poisonous lizard in existence. A recent memoir by Dr. Shufeidt (P.Z.S. I 890, p. I 48) has supplied a good deal of information respecting the anatomy of this lizard. The large poison glands are shown to lie on either side of the lower jaw, their ducts opening into the floor of the mouth, whence it is surmised that the poisonous secretion finds its way along the grooved teeth of the mandible to the inflicted wound. It is a curious fact that although some of the teeth of the upper jaw of this Lizard are also grooved, no trace of any poison gland has been found here. An interesting account of the effects of the bite of the Heloderm on the human subject has been already recorded in our pages (NATURE, vol. xxvii. p. 154), and

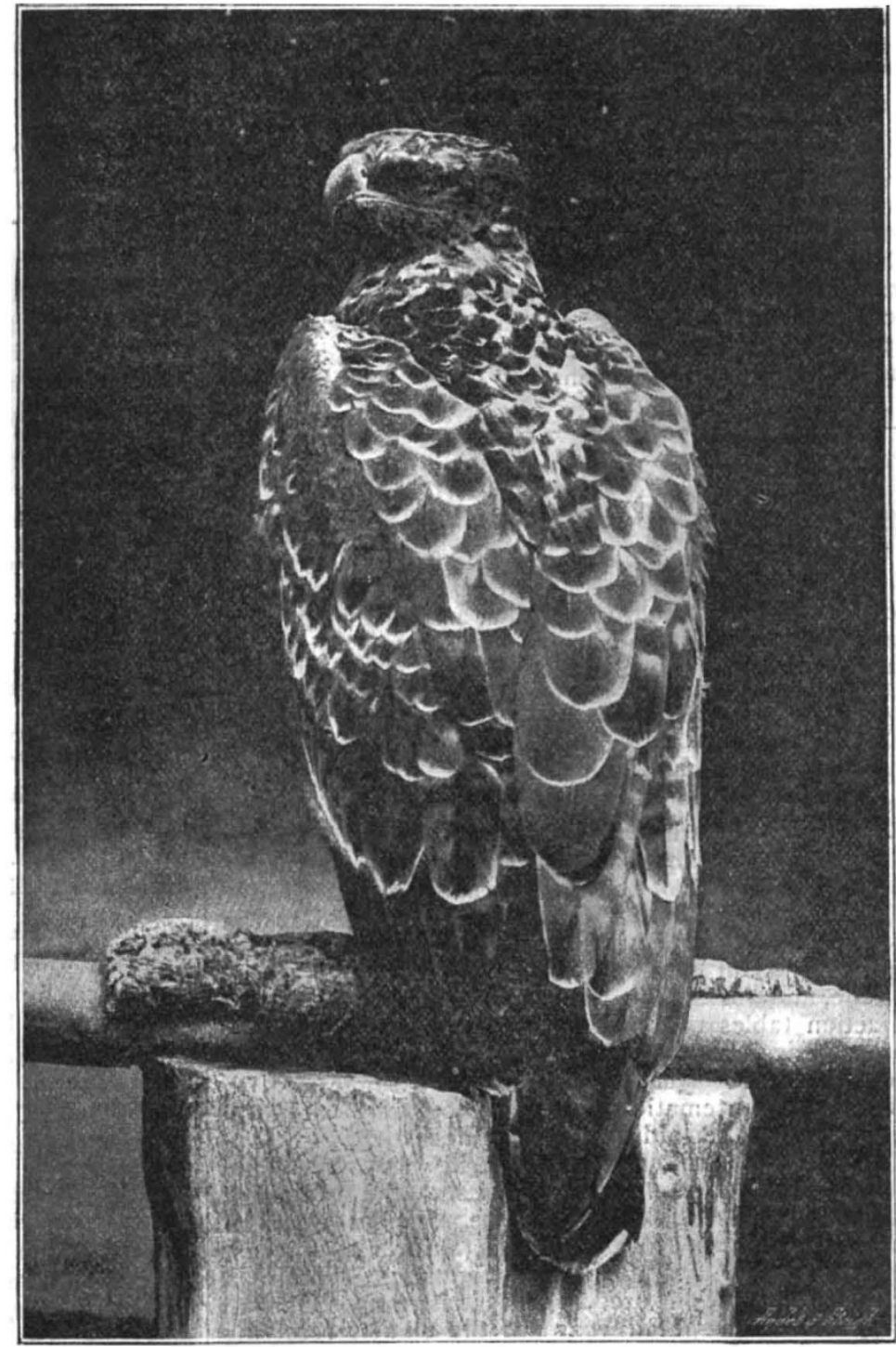

FIG. 2.-The Martial Hawk Eagle.

$$
\text { No. I } 316 \text {, vOI. } 51]
$$

it has been shown that its effects on man, though painful at the time, are not of a serious nature.

One of the very few statements in this work with which we are unable to agree, is to be found in the account of the diving birds at the Zoo. With regard to the Penguin, Mr. Cornish says: "It cannot fly in the air ; it cannot walk, but hops as if its feet were tied together; it cannot even swim." If Mr. Cornish will turn to the account of the expedition of the Dundee whalers to the Antarctic Seas, given in the Scottish 
Geographical Magazine for February 1894, he will find the following passage: "On one occasion, in the north of the Erebus-and-Terror Gulf, we saw large schools, numbering 300 to 500 , of the common black-throated Penguin, swimming together; the movements of each school being controlled by a single individual of larger size, which followed in the rear." It is quite possible that this error may have arisen through the fact that, as a rule, the Penguins, when allowed, in the Zoological Gardens, to enter their tank, dive straight off the board leading into the water, and remain under water until all the fishes in the tank are caught and devoured. After that they usually betake themselves straight back to the board. But that they can swim duck fashion, when they wish to do so, admits of no doubt whatever.

The volume is illustrated by a series of Gambier Bolton's photographs, which are certainly the best ever taken of "Life at the Zoo." Of these we are kindly permitted to reproduce two. One of them represents the Tiger "listening to soft music," and forms part of a series made to illustrate "Æsthetics at the Zoo." The other shows the Martial Hawk Eagle, a rather rare bird from South Africa. On the whole, we can cordially recommend this volume for readers of the lighter literature of Natural History, and even as containing a certain amount of novel information on "Life at the Zoo."

\section{INTERCOLONIAL ASTRONOMY AND METEOROLOGY.}

$\mathrm{W}^{\mathrm{E}}$

E learn from Mr. R. L. J. Ellery, F.R.S, that a conference representing the three colonies of New South Wales, South Australia, and Victoria, met at the Observatory, Melbourne, on October 29. Mr. H. C. Russell, F.R.S., from Sydney, and Sir Charles Todd, F.R.S., from Adelaide, were present.

(I) As regards Australian standard time, it was resolved to advise the respective Governments to adopt for that purpose the time of the meridian of $150^{\circ} \mathrm{E}$.

It was also agreed to advise that the changes from one hour zone to another shall take place at the eastern and western boundaries of the several colonies.

(2) A proposal, by Sir C. Todd, was adopted to the effect that the three observatories should co-operate in a special series of observations for determination of colatitude, and for testing the applicability of the present refraction tables to astronomical work at the various observatories.

(3) It was resolved, at Mr. Russell's suggestion, to carry out systematic cloud photography at each observatory, as an aid to weather forecasting.

(4) As to agricultural forecasts, it was agreed to: "That in each of the colonies represented a forecast of the weather shall be sent to all the principal telegraph stations each day, except Sunday (Saturday's forecast being for 48 hours), and that forms to contain a week's forecasts be used, which it is proposed shall be posted on a special board at the station receiving forecasts."

(5) It was resolved that the storm signals to be used be the same as used in England.

(6) On the suggestion of Mr. Russell, it was agreed that further determination of the differences of longitude of Adelaide, Melbourne, and Sydney, should be carried out, and that periods when there was high atmospheric pressure at one place, and low at another, be selected for the operations, with the view of ascertaining if large differences of atmospheric pressure between the eastern and western stations had any influence on the longitude results. Mr. Russell undertook to draw up a programme for this undertaking.

$$
\text { No. } 13 \text { I6, voL. } 5 \text { I }]
$$

\section{NOTES.}

ENGLISH geologists will be gratified to learn that the veteran Prof. Prestwich has been elected a Vice-President of the Geological Society of France. It is, we believe, the second time only that this honour has been conferred on one who was not a French subject. The Council of the Geological Society of London has formally offered to Prof. Prestwich its congratulations on the distinction thus received.

M. MAscart has succeeded M. Tisserand as President of the Paris Société d'Encouragement.

THE death is announced of Prof. Karl v. Haushofer, Director of the Technische Hochschule at Munich, and Professor of Mineralogy in the University of that city.

DR. G. M. Dawson, C.M.G., F.R.S., has been appointed Director of the Geographical Survey of Canada, in succession. to Dr. A. R. C. Selwyn, who has been superannuated.

WE regret to note that the Duke of Argyll was attacked by sudden indisposition while addressing a meeting at Glasgow on Tuesday evening. His condition at first gave rise to serious concern, and it was not till a late hour that he recovered sufficiently to be conveyed to the residence of Lord Kelvin, where he is staying.

At Fishmongers' Hall, this evening, the Marquis of Lorne will present the prizes and certificates obtained by students in connection with the City and Guilds of London Institute.

THE twenty-second annual dinner of the old students of the Royal School of Mines will be held on Friday, January 25, at the Criterion Restaurant. A number of distinguished visitors are expected to be present, and arrangements have been made for a large gathering of associates and old students.

THE annual meeting of the People's Palace Chemical Society will be held on Thursday, January 24, when Dr. T. E. Thorpe, F.R.S., will give an address on "Some causes and conditions' of chemical change." The chair will be taken by Prof. Tilden at $8 \mathrm{p} . \mathrm{m}$. Tickets may be obtained by application to the hon. sec., Mr. Thomas Yetton.

THE Association for the Improvement of Geometrical Teaching will hold a general meeting at University College, Gower Street, next Saturday. In the morning, the report of the council will be read, and the new officers will be proposed for election. During the day, papers will be read on "Algebra in Schools," "The Association's Syllabus of Geometrical Conics," "The Conics of Apollonius," and "Notes on Mensuration."

THE forty-eighth annual general meeting of the Institution of Mechanical Engineers will be held on Thursday evening, January 3I, and Friday evening, February 1 . The annual report of the Council will then be presented, and the election of the President, Vice-Presidents, and Members of Council will take place. The following papers will also be read and discussed, as far as time permits :- "The Determination of the Dryness of Steam," by Prof. W. Cawthorne Unwin, F.R.S. ; "Comparison between Governing by Throttling and by Variable Expansion," by Captain H. Riall Sankey.

THE freshwater biological station, which was established at Plön three years ago through the efforts of Dr. Otto Zacharias, seems to be assuming quite an international character. From a recent report of the director, we learn that nine investigators worked at the station during the summer semester of last year, and of these four were German, two English, two French, and one Russian. Much interesting work seems to have been 